\section{Neural tube defects}

SIR,

I read the correspondence from Drs Field and $\mathrm{Kerr}^{1}$ with interest. We studied some neural tube defect (NTD) affected sib pairs from the USA and analysed them with reference to the concordance of a specific NTD in the second affected sib. ${ }^{2} I$ applied the same analysis to these Australian data and made the following observations. If all affected sib pairs are pooled there is a highly significant relationship between the specific NTD in the first and next affected child. Using the Mantel-Haenszel test, $T$ lies between 2.87 and 3.11 and p between 0.0018 and 0.0040 . In fact only one to three sib pairs are non-concordant for the same NTD. When the group is separated by the sex of the first affected child, the probability of concordance remains significant if the first affected is male ( $p=0.0145$ by Fisher's exact test), but not when the first affected child is female $(p=0.0726)$.

These data are similar to ours and this analysis supports the suggestion that NTD in affected females has a stronger environmental influence than that in males. (One might suspect that the recurrence risk will differ accordingly.) The distribution of NTDs in a second child, spina bifida versus anencephaly, is not always equal for both defects, as often stated.

I cannot comment on season and interval as this information is not available on our patients.

\section{SUSAN Cowchock Division of Medical Genetics, Jefferson Medical College, Suite 710 College, 1025 Walnut Street, Philadelphia, Pennsylvania 19107, USA.}

\section{References}

1 Field B, Kerr C. Season and interval for recurrence of neural tube defects. J Med Genet 1981;18:484.

2 Cowchock S, Ainbender E, Prescott G, et al. The recurrence risk for neural tube defects in the United States: a collaborative study. Am J Med Genet 1980;5:309-14.

\section{Proximal 15q monosomy}

SIR,

Having seen the letter from Dr Arabella Smith ${ }^{1}$ highlighting the problem of incomplete searching of the literature in the correlation of cytogenetic case reports, I was interested to read her report ${ }^{2}$ of a case in which the deletion of chromosomes $15(\mathrm{pter} \rightarrow \mathrm{q} 13)$ and $10(\mathrm{q} 26 \rightarrow \mathrm{qter})$ resulted from a reciprocal translocation.

In this paper she cites only one similar case of $15 q$ monosomy and concluded that "more cases are needed before a proximal $15 q$ - syndrome can be delineated". However, I know of 12 further previously published reports involving a translocation, with monosomy ranging from 15 (pter $\rightarrow$ q11) to 15(pter $\rightarrow$ q21), and two with an interstitial deletion of the proximal long arm of chromosome 15 (reviewed by Duckett and Roberts ${ }^{3}$ ). Because of some variation in the degree of loss of 15 material and, more significantly, the association with other chromosomal imbalance, we were unable to correlate specific phenotypic abnormalities in all cases with this type of partial monosomy 15 . We did, however, note that four of these reports, together with another unpublished case, were associated with Prader-Willi syndrome, and drew attention to the proposal in one of them ${ }^{4}$ that deletion of $15(\mathrm{q} 11 \rightarrow \mathrm{q} 13)$ causes Prader-Willi syndrome. I am currently aware of 10 cases involving a detectable deletion of at least the proximal portion of $15 \mathrm{q}$ which are associated with Prader-Willi syndrome (Duckett et al, in preparation).

Further, Smith and den Dulk ${ }^{2}$ quote a book published in 1977 as evidence of the absence of other cases of monosomy 10q. This approach would seem to be unacceptable in this type of report. While I have not made a literature search of cases with monosomy of the distal long arm of chromosome 10, two such publications are cited in Borgaonkar. ${ }^{5}$

Finally, Smith and den Dulk ${ }^{2}$ suggest in their report that the most likely explanation of the $45, \mathrm{XY}$, $-10,-15,+t(10 ; 15)(q 26 ; q 13)$ karyotype found in peripheral blood of the proband is a de novo balanced reciprocal translocation with post-zygotic loss of the smaller translocation product, the balanced karyotype possibly still being present in other tissues and perhaps having accounted for the mental retardation and phenotype. I consider that a more probable explanation of the karyotype would be a de novo 3:1 meiotic disjunction of the tertiary monosomic form in a parental germ cell, as proposed by Lindenbaum and Bobrow. ${ }^{6}$ This theory is supported by (1) the absence of mosaicism in the peripheral blood and (2) the nature of this reciprocal translocation which would be predisposed to a 3:1 disjunction. ${ }^{6} 7$

\section{DAVID P DucketT \\ Cytogenetics Unit, Department of Child Health, University Hospital of Wales, Heath Park Cardiff CF4 $4 X W$.}

\section{References}

1 Smith A. Gonadal dysgenesis with 46,X,Xt(qter $\rightarrow$ p221 : p223 $\rightarrow$ qter) karyotype. $J$ Med Genet $1981 ; 18: 400$. 
${ }^{2}$ Smith A, den Dulk G. A severely retarded male with deletion of chromosomes 15 (pter $\rightarrow$ q13) and 10(q26 $\rightarrow$ qter). J Med Genet 1982;19:77.

3 Duckett DP, Roberts SH. Adjacent 2 meiotic disjunction. Report of a case resulting from a familial $13 q ; 15 q$ balanced reciprocal translocation and review of the literature. Hum Genet $1981 ; 58: 377-86$.

4 Ledbetter DH, Riccardi VM, Airhart SD, Strobel RJ, Keenan BS, Crawford JD. Deletions of chromosome 15 as a cause of the Prader-Willi syndrome. $N$ Engl J Med $1981 ; 304: 325-9$.

5 Borgaonkar DS. Chromosomal variation in man. A catalog of chromosomal variants and anomalies. 3rd ed. New York: Alan R Liss, 1980.

6 Lindenbaum RH, Bobrow M. Reciprocal translocations in man. 3:1 meiotic disjunction resulting in 47- or 45chromosome offspring. $J$ Med Genet 1975;12:29-43.

7 Jalbert P, Sele B, Jalbert H. Reciprocal translocations: a way to predict the mode of imbalanced segregation by pachytene-diagram drawing. A study of 151 human translocations. Hum Genet 1980;55:209-22.

\section{Note added in proof}

Since submission of this letter, Ledbetter et $\mathrm{l}^{8}$ have reported a further 19 cases of interstitial deletion of proximal 15q material in a series of 40 patients with Prader-Willi syndrome.

\section{Reference}

8 Ledbetter DH, Mascarello JT, Riccardi VM, Harper VD, Airhart SD, Strobel RJ. Chromosome 15 abnormalities and the Prader-Willi syndrome: a follow-up report of 40 cases. Am J Hum Genet 1982;34:278-85. 